early introduction would have simplified much of the previous chapters. They felt, however, that the juxtaposition of the classical technique and the more modern one should be very helpful, and the reviewer agrees with them wholeheartedly. Six valuable appendixes conclude the text.

The book would have been more satisfying had more space been devoted to brief critical accounts of physical principles and definitions. For example, the orders of magnitude of the variation of conductivity and specific heat with temperature might have been discussed and, where known, the results of taking these variations into account might have been compared with the result of assuming these quantities to be constants. Or again, the note on the effect of turbulence on the coefficient of outer conductivity might have been amplified.

The authors have written on a difficult subject. They have formulated their plan with care and have kept to it. Others, including the reviewer, might have preferred a more physical approach without the sacrifice of any of the mathematical ingredients of the publication, but this is purely a matter of opinion. Carslaw and Jaeger are to be congratulated upon this addition to the literature of the conduction of heat in solids, and note should be taken of the compliment paid by Prof. Carslaw to his junior colleague, Dr. Jaeger, when he says in the preface "He is most certainly its principal author".

This review would not be complete without a special note of praise for the printing and binding. Those whose work involves a close scrutiny of scientific texts are indebted to the Oxford University Press for the continuation of its high standards even in times of great difficulty.

L. ROSENHEAD

\section{THE NEUROTIC PERSONALITY}

Dimensions of Personality

By Dr. H. J. Eysenck. A Record of Research carried out in collaboration with Dr. H. T. Himmelweit, Dr. W. Linford Rees, and with the help of Dr. M. Desai, W. D. Furneaux, H. Halstead, Dr. O. Marum, M. McKinlay, A. Petrie and P. M. Yap. Pp. xi +308. (London : Kegan Paul and Co., Ltd., 1947.) 25s. net.

7 HIS book is based upon research carried out by a team of psychologists working at the Mill Hill War Emergency Hospital. The object of their investigations was to discover the relationship of various traits of personality to 'neuroticism'. The experiments were performed on a group of patients, numbering seven hundred, suffering from reactive types of mental illness. The statistical method was used, and careful correlations are given for the various traits.

The authors state that two main facts emerge from their study. First, there is a general factor, 'neuroticism', shown by signs of a badly organised personality, poor muscular tone, pre-service evidence of abnormality, abnormal parents and unsatisfactory homelife. Secondly, a bipolar factor with affective type of symptoms (anxiety, depression, obsessional tendencies, etc.) at one end and hysterical type (conversion symptoms, sex anomalies, low intelligence, bad. work history, hypochrondriasis, etc.) at the other.

A number of studies were made upon physique and constitution, such as body build, autonomic activity, dark vision, choline esterase secretion and exercise response. The authors claim significant differences between the two groups. Other studies were made upon neurotics and non-neurotics with regard to intelligence, accuracy of work, level of aspiration and so on. These tests are claimed to differentiate dysthymics frorn hysterics and normals from neurotics.

Tests were also made upon various types of suggestibility and the relation of them to hysteria. The authors believe that there is no evidence that hysteries are more suggestible than other neurotics. They found, however, that suggestible patients were made more so by narcotics, whereas non-suggestible ones remained unaffected. In the experiments made upon appreciation and expression it was found that neurotics were more reactive to colour, but there was no difference between the hysteric and the dysthymic.

These tests may arouse some readers to complain that the mind is so fractionated in such a study that nothing much is proved. Prof. Aubrey Lewis, in the brief foreword, answers this objection that the methods are 'atomistic', and points out that it is an attempt at "the analysis, by reliable statistical techniques, of experimental and clinical data, so that measurement may be possible and a sight obtained of the promised land where mental organisation will be as well understood as the physical organisation of human beings is".

This research is interesting, and the frequent quotations show a wide knowledge of the literature. A few show an unnecessary desire to quote from other Maudsley colleagues, as, for example, that on page 51 : "A person's constitution may render him liable to breakdown at the slightest provocation; on the other hand, a person of first-class constitution may finally break down when the stress is too great." This is such a psychiatric commonplace that surely it has been stated many times before Slater in 1944 . These, however, are minor blemishes and the book as a whole is valuable.

The format is neat, the paper good and the printing clear. It is written as easily as such a subject allows. There is a useful summary of the findings at the end of each chapter and many diagrams clarify the text. There is a long bibliography of 24 pages and an excellent index.

CLIFFORD ALLEN

\section{"CUSHNY'S PHARMACOLOGY"}

\section{Pharmacology and Therapeutics}

Originally written by Prof. Arthur R. Cushny. Thirteenth edition, thoroughly revised by Prof. Arthur Grollman and Dr. Donald Slaughter. Pp. 868. (London: J. and A. Churchill, Ltd., 1947.) 458. W $\begin{aligned} & \text { HEN Cushny's text-book first appeared in } 1899 \text {, } \\ & \text { it was recognized as being "the first severely }\end{aligned}$ critical, rigorously scientific general text-book to be written in English by an experimental pharmacologist". It helped to put the science of pharmacology on secure foundations by eliminating traditional lore and concentrating attention on proved facts. It became the standard text-book in English on both sides of the Atlantic, and Cushny himself was responsible for eight editions. After his death in 1926, four more editions were prepared jointly by Prof. J. A. Gunn of the University of Oxford and Prof. C. W. Edmunds of the University of Michigan. The thirteenth edition, which has recently appeared, is a purely American production. Most of the work of revision has been done by Prof. Arthur Grollman, 